\title{
The effectiveness gap in COPD: a mixed methods international comparative study
}

\author{
*Nick Bosanquet ${ }^{1,2}$, Lucy Dean², Irina lordachescu², Colm Sheehy ${ }^{2}$ \\ ${ }^{1}$ Department of Bioengineering, Imperial College London, London, UK \\ 2 Volterra Partners, London, UK
}

Received 12th October 2012; revised 3rd January 2013; accepted 14th January 2013; online 2nd April 2013

\begin{abstract}
Background: There has been a large increase in treatment and in research on chronic obstructive pulmonary disease (COPD) from the common starting point of the original Global Initiative for Chronic Obstructive Lung Disease (GOLD) study. There is currently little evidence on the degree of similarity and difference between national programmes or on the linkage between research and policy.

Aims: To review the evidence on programme development and the effectiveness gap from the UK, France, Germany, and Finland.

Methods: Visits and literature reviews were undertaken for regional centres in Lancashire, Nord-Pas de Calais, and Finland, Eurostat data on mortality and hospital discharges were analysed, and telephone interviews were conducted in Nord-Rhein Westphalia.

Results: There have been very significant differences in programme development from the original GOLD starting point. The UK has national strategies but they are without consistent local delivery. The French Affection de Longue Durée (ALD) programme limits special help to at most $10 \%$ of patients and there is little use of spirometry in primary care. Germany has a more general Disease Management Programme with COPD as a late starter. Finland has had a successful 10-year programme. The results for the effectiveness gap on hospital discharges show a major difference between Finland (40.7\% fall in discharges) and others (increases of 6.0-43.7\%).

Conclusions: The results show the need for a simpler programme in primary care to close the effectiveness gap. Such a programme is outlined based on preventing the downward spiral for high-risk patients.

(C) 2013 Primary Care Respiratory Society UK. All rights reserved.

N Bosanquet et al. Prim Care Respir J 2013; 22(2): 209-213

http://dx.doi.org/10.4104/pcrj.2013.00035
\end{abstract}

Keywords COPD, effectiveness gap, UK, France, Germany, Finland, sociotype, phenotype

\section{Introduction}

Over the last 15 years the diagnosis of chronic obstructive pulmonary disease (COPD) has become widely accepted internationally. The original Global Initiative for Chronic Obstructive Lung Disease (GOLD) report in 2001 alerted nations to the emergence of a new and major threat from lung disease following the decline of tuberculosis. ${ }^{1}$ This resulted in the development of strategies and services on a much greater scale than in the 1980s and 1990s across the developed world. The main emphasis after GOLD seems to have been on improving diagnosis at the initial stage through the use of spirometry.

The 2011 revision of the GOLD document points to a new phase of service development with much more emphasis on the longer term development of care programmes. ${ }^{2}$ Confidence in the accuracy of spirometry appears to have reduced with the emergence of new measures of risk factors with a wider range of variables, but paradoxically there seems less emphasis on the social and psychological aspects of COPD. The key diagram in GOLD 1 on the downward spiral - 'The Cycle of Physical Social and Psychological Consequences of COPD' - was not carried over to GOLD 2.,3

New research has emerged which supports the emphasis on sustained care programmes. The ECLIPSE study shows that the prevention of exacerbations is a vital aim since exacerbations bring higher mortality and irreversible loss of lung function. ${ }^{4}$ Data from the TORCH study have shown that poor adherence to medication is a major predictor of mortality and of hospital admission. ${ }^{5}$ Of the 4,880 patients with good adherence, $11.3 \%$ died compared with $26.4 \%$ of the 1,232 patients with poor adherence.

This paper reviews evidence from four countries - UK, France, Germany and Finland - on the linkage between service development and policy after the first GOLD report, and considers the following questions:

\footnotetext{
* Corresponding author: Professor Nick Bosanquet, Emeritus Professor of Health Policy, Department of Bioengineering, Imperial College London, Exhibition Road, London SW7 2AZ, UK. Tel: +44 (0)20 75943355 E-mail: n.bosanquet@imperial.ac.uk
} 
- From a common starting point, how consistent was the development of programmes?

- How far were there common measures of effectiveness?

- Can we measure the results and achievements from substantial extra expenditure?

The paper then reviews the evidence on the effectiveness gap between the four health systems and sets out options for narrowing it. The new evidence points to the need for a second generation of programmes which will reduce the effectiveness gap.

\section{Methods}

A review was carried out of the papers cited in the first GOLD report and on surveys carried out since. This aimed to establish the key research findings which had impacted on policy makers since the acceptance of COPD as a common diagnosis supplanting the older categories of bronchitis and emphysema. Key documents were then retrieved on strategies and service development within the four health systems. The search covered both documents on national strategy and regional reports for three older industrial areas - North West England, Nord-Pas de Calais, and the Ruhrgebiet/Nord-Rhein Westphalia. The search covered documents produced by health agencies and professional groups over the last 10 years. UK data show that the prevalence was three times as great in older industrial areas, $^{6}$ which confirms the relevance of focus on such areas. We summarise from the documents whether such findings have led to any special programmes for such areas.

Visits were made to meet health professionals and review services in the UK, France, and Finland, and telephone interviews were carried out for Germany. During the visits, further reports were collected on local service initiatives which are not generally available in national data sources. Particularly notable were the protocols for the services provided by the hospital in Pourvoo, Finland ${ }^{7}$ and the report of the Agènce Regional de Santé for the Nord-Pas de Calais. For the UK there were more national strategies and guidelines from the Department of Health and from the National Institute for Health and Clinical Excellence (NICE). The best documentation was to be found in Finland, which included both proposals and a 10-year evaluation of the national strategy for COPD.

In France we carried out seven interviews with health professionals and reviewed 10 reports and papers; in Finland there were 10 interviews and eight reports/papers; in Germany there were five interviews and four reports; and in England eight interviews and 15 reports/papers were carried out.

A full measure of effectiveness would require data on six different performance measures:

- Prevalence

- Numbers undiagnosed

- Premature mortality

- Survival curves

- Levels of exacerbations

- Levels of hospital discharges

However, no comparable data are available to allow reliable international comparisons for five of these variables. The exception is the variable of hospital inpatient discharges. For this, data were sourced from Eurostat for all four countries; the UK data were supplemented by HES online. Data were collected for COPD hospital discharges in the most recent available year from 2000 until 2009. The data for 2009 hospital discharges in Germany were not available so the 2008 data were used as a proxy.

\section{Results}

UK

In the UK, structured programmes for COPD started at least 10 years later than those for heart disease. Even before the National Service Framework for coronary heart disease in 1999, there had been disease management programmes in Wales and East Kent. ${ }^{8}$ For a long time, bronchitis was seen as a legacy disease which would die out with a generation.

The publication of the first GOLD strategy in 2001 did not have any immediate policy response but by 2004 it had a significant impact in the Quality and Outcomes Framework for GPs. This has five points relating to COPD: availability of a practice register; use of spirometry; updating of spirometry; assessment of dyspnoea using the Medical Research Council (MRC) score; and coverage of influenza vaccination. ${ }^{9}$

Local initiatives developed around smoking cessation and rehabilitation programmes. In 2012 the National Health Service (NHS) has seen two major documents on new standards, both setting out longer term care programmes: NICE has produced a quality standard for COPD, ${ }^{10}$ and the UK Department of Health has produced an outcomes strategy which stresses a 'call to action' to 'galvanise the collective efforts of the health system, professionals, people with COPD and the public to fundamentally change the burden of COPD'. ${ }^{11}$ The REACT policy covers: respiratory health and good lung health; early accurate diagnosis; active partnership between health professionals and people with COPD; chronic disease management; and tailored evidence-based treatment.

The new initiative takes place against a background of continuing concern about patient care in the UK, with data from the World Health Organization showing that premature mortality from COPD was almost twice as high in the UK as in the rest of Europe.

\section{France}

As in the UK, service improvement started from the first GOLD report. Since then there have been guides/protocols (2006 and 2012) from the Haute Autorité de Santé. The 2012 guide is much more detailed on the initial diagnosis and the support programme for patients with stable COPD. ${ }^{12}$ It also sets out instructions for the treatment of patients in exacerbations, advising the use of bronchodilators rather than antibiotics and setting criteria for admissions.

Support programmes such as rehabilitation are only available to those patients who are registered by their doctors as a patient with 'affection de longue durée' (ALD). Patients with severe COPD are eligible, and there are 40,000 registered for ALD compared with at least 800,000 who are likely to have COPD, with an estimated prevalence of $7.5 \%$ in the population aged $>40$. The ALD group are entitled to a wider range of services paid for by insurance and can avail themselves of a more comprehensive assessment. Other patients are treated by the primary care doctor. There is no 
information available on the actual use of services by the ALD group.

The Nord-Pas de Calais region includes old mining areas. A collaborative group led by $\mathrm{Dr}$ Vincent Van Bockstael, Strategy Director of the Agènce Regional de Santé, recently published a regional strategy for 2012-2016. This report breaks new ground in the research evidence for its recommendations on treatment and drug therapy.13 The starting point of the report is the need to improve services which seem to be a long way from the standard set in the 2012 guide. The report signals that there is much underdiagnosis, little use of spirometry, and referral to specialists often takes place very late at stage 3 . The report is critical of tiotropium use. It also reports that only 700 people attended hospital rehabilitation programmes in the whole region with a population of two million.

\section{Germany}

Although the GOLD reports are well known in Germany, service development owes more to the more generic Initiative on Disease Management. ${ }^{14}$ In 2001 a Government Commission criticised the dominance of acute care and the lack of prevention and rehabilitation. The government responded quickly with a Disease Management Programme (DMP) which covers 32 different conditions including breast cancer and heart disease. Doctors have to attest that they have carried out the activities prescribed in the contract. The priority areas were breast cancer, heart disease, and diabetes. It is estimated that $65-70 \%$ of those with type 2 diabetes are registered under DMP, but it is likely that COPD registration is much less.

Audit covers initial registration and little is known by the insurance funds about longer term follow-up. There are no special programmes for older industrial areas and information on regional and local prevalence is not available. However, a recent survey of the quality of life of patients with long-term conditions showed that 'chronic bronchitis had very serious effects'. 'The conditions with the greatest negative impact on the EQ-5D index were history of a stroke and ... chronic bronchitis'. ${ }^{15}$ The most important impact of the DMP has been in defining more clearly the role of primary care doctors, who are now seen as the main managers of COPD care with much clearer guidelines on referral.

Parallel to the DMP, a group of specialists have published detailed guidelines, 'National VersorgungsLeitlinie fur COPD', ${ }^{16}$ which present a detailed treatment programme for each stage in line with international best practice. There is no evidence on take up. In the German health system there are no signs of distinct regional programmes or local initiatives. The national DMP only fully covers initial assessment.

\section{Finland}

Finland has set international benchmarks for effective programmes both in COPD and in asthma. There was a 10-year programme which started well before the GOLD report. ${ }^{17}$ The aims of the programme were reduction in prevalence, improvements in COPD diagnosis (especially in primary care), reduction in the number of moderate to severe cases, reduction in hospitalisation, and reduction in treatment cost. This programme in the 1990s was unique to Finland, following on the success of prevention and treatment programmes in North
Karelia. ${ }^{18}$ Designated doctors and nurses in each of the 271 primary care centres in Finland were responsible for improving care.

The prevalence of COPD remained unchanged. Smoking decreased in males from $30 \%$ to $26 \%$ and in females from $20 \%$ to $17 \%$. There were significant improvements in spirometry, hospitalisation days decreased by $39.7 \%$, with discharges falling by $37.6 \%$. The number of hospital days fell from 34,600 to 18,000 . Total costs fell and the cost per patient decreased by $36 \%$. This followed the success of the asthma programme in Finland. ${ }^{19}$

Since 2007 there have been no new national programmes but some new local programmes such as those at Pourvoo Hospital. This involved selecting high-risk patients for intensive help with medication adherence, smoking cessation, and activity programmes.

\section{The effectiveness gap}

Among measures of the effectiveness gap there are two for which some data have been collected on a consistent basis across countries. Mortality is one possible measure but may be subject to bias from differential diagnoses on death certificates. From 2001 and 2010, COPD mortality (per 100,000 population) fell slightly (by 3.3\%) in the UK, in France it increased by $5.7 \%$, and in Finland it fell by $2.7 \%$; in Germany it rose by $34.3 \%$, but this may be a result of increased use of the COPD diagnosis. We therefore did not put much emphasis on this variable.

Hospital discharge (per 100,000 population) is our preferred indicator of effectiveness. ${ }^{20}$ Hospital discharge is a sign of exacerbations, and recent research such as the ECLIPSE study has shown that a reduction in exacerbations is very important for COPD patient health. ${ }^{4}$

The data clearly show that the number of discharges has risen in the UK, France and Germany and fallen in Finland by $40.7 \%$ between 2000 and 2009 (Table 1). Overall, the data support the undeniable success of Finland's 10-year plan for reducing the effectiveness gap by improving the primary care system to enable more effective diagnosis and treatment.

In the UK both hospitalisation and mortality rates remain high, and in the UK, France and Germany increased discharges are evidence of a rising toll from exacerbations. There are no significant differences in admission rates in the older industrial areas. Given the higher prevalence and risk factors, this may point to a significant burden of disease in the community or to untreated illness.

Finland provides the benchmark for effectiveness with a $40.7 \%$ reduction in discharges. The UK retained the highest level of discharges throughout with a $6 \%$ increase. France has a low level of discharges, but this may be the result of under-diagnosis as up to

Table 1. Hospital COPD inpatient discharges per 100,000 population

\begin{tabular}{lllll} 
& Germany & France & Finland & UK \\
\hline Change 2000-2009 & $43.7 \%$ & $9.7 \%$ & $-40.7 \%$ & $6.0 \%$ \\
\hline 2000 actual & 181.9 & 85.7 & 260.4 & 218.2 \\
\hline 2009 actual* & 261.4 & 94.0 & 154.3 & 231.4 \\
\hline \multirow{5}{*}{ *Germany 2009 value not available so 2008 value used }
\end{tabular}


$76 \%$ of French patients with COPD have not received a diagnosis from their primary care practitioner. ${ }^{12}$ In Germany, hospital discharges have shown a rapid increase. These results suggest that, apart from Finland, there is currently little success in reducing exacerbations. There is a very distinct 'effectiveness gap' between the Finland standard and the discharge trends elsewhere.

\section{Discussion}

\section{Main findings}

The results show that there has been more activity and more prescribing which may have been of most help for those patients with less severe COPD, but there are few signs of success for improving outcomes for those most at risk from exacerbations, apart from the results in Finland. There is acceptance in all four countries that primary care must be the main service for patients with COPD, yet hospitals in three of these countries have been treating more patients with rising costs.

\section{Strengths and limitations of the study}

The study benefited from discussions with local professionals working in the key regions. They give a realistic perspective which may be different from the wish lists or Sunrise Compliance documents which often form the main output of national policy discussions. One limitation of the study is the lack of data on the patient experience over time and on the social and personal disease costs.

\section{Interpretation of findings in relation to previously published work}

Recent research such as the ECLIPSE study has shown that prevention and timely management of exacerbations is key to improved results at the local level. The study provides confirmation that it is possible to design local programmes which can deliver effective results in relation to this new aim.

\section{Implications for future research, policy and practice}

There could be international collaboration to develop a simple model programme for use in primary care. The aim would be to match the results of Finland over a five-year time period. There is already some good practice in all the four countries studied. A common programme would be able to draw on the smoking cessation programmes in the UK and home activity programmes in France.

The programme could include a simple tool for risk stratification which could bring together clinical and patient factors and assist in identifying high-risk patients in need of support and follow-up. It is vital to identify high-risk patients since there is unlikely to be the time, or the staffing levels, to give more intensive help to all patients.

A risk stratification score could be developed from the various indicators already in use. It could cover a range of medical and social variables which would identify those patients most at risk of a downward spiral. We may discover a phenotype related to exacerbations in the future, but we already have a sociotype which is clearly a strong predictor of exacerbation risk.

The risk assessment could be used both for initial assessment and to measure change over the course of the disease. The programme would have sections for regular review. It would also include sections for review of drug utilisation and for monitoring adherence to inhaler and drug therapy. Reduction of exacerbations and prevention of discharges would be the obvious measures of progress.

The COPD kit would include a personal care programme and emphasis on patient self-help and carer support. It would include advice on smoking cessation, messages on inhaler technique, and simple exercises for improving lung function which could be done at home. It would also set up communication with primary care doctors or specialist nurses. The aim would be to support motivation and a sense of responsibility for maintaining the patient's own fitness and well-being.

The programme could be used as part of a targeted programme to improve health in older industrial areas such as Lille, Pas de Calais, and the North-West region of the UK. To these could be added older industrial areas worldwide such as Appalachia in the USA, Manchuria, Mumbai, and the copper mining areas of Chile.

The programme would be adapted to the increasing number of women with COPD. More information is needed on disease impacts and the special problems of female patients. They form an increasing proportion of COPD patients and, according to evidence from the ECLIPSE study, are more likely to have exacerbations.

The programme should also include help and advice to carers vital contributors in terms of motivation and co-management.

The programme would develop the role of pharmacy in support of COPD patients. This could involve initial support in the use of inhalers and longer term follow up. Pharmacies could also sell support kits for home exercise programmes including home exercise programmes.

The new programme is urgently required in providing a better link between research and practice and could lead to the steady improvement in results for patients. There is now clearly evidence from Germany and elsewhere of the very serious effects of COPD on quality of life: the potential is there for an effective primary led programme which could transform prospects for many patients.

\section{Conclusions}

We could be entering a new and positive period with COPD treatment programmes offering new hope for patients. This could be an important area of care where a small targeted investment could bring very significant returns.

\section{Handling editor Hilary Pinnock \\ Statistical review Gopal Netuveli}

Acknowledgements We would like to express our warm thanks to the health professionals and patients who helped with the research and to Prof J.Vestbo, Dr D Leather and A.Tynan.

Conflicts of interest The authors declare that they have no conflicts of interest in relation to this article.

Contributorship NB is the main author. LD, II, and CS from Volterra carried out literature reviews, data searches, and initial drafts of country studies. All authors participated in the writing process and provided data. NB carried out all interviews and country visits.

Funding Financial support is acknowledged from a research grant from GlaxoSmithKline (GSK). NB is an associate of Volterra. The drafting of the paper was entirely independent of GSK.

\section{References}

1. Global Initiative for Chronic Obstructive Lung Disease (GOLD). Global Strategy for the 
Diagnosis, Management and Prevention of Chronic Obstructive Pulmonary Disease. 2001.

2. Global Initiative for Chronic Obstructive Lung Disease (GOLD). Global Strategy for the Diagnosis, Management and Prevention of Chronic Obstructive Pulmonary Disease. 2011.

3. Global Initiative for Chronic Obstructive Lung Disease (GOLD). Global Strategy for the Diagnosis, Management and Prevention of Chronic Obstructive Pulmonary Disease. 2001. p. 74.

4. Hurst JR, Vestbo J, Anzueto A, et al. Susceptibility to exacerbation in chronic obstructive pulmonary disease. N Engl J Med 2010;363:1128-38. http://dx.doi.org/10.1056/NEJMoa0909883

5. Vestbo J, Anderson JA, Calverley PM, et al. Adherence to inhaled therapy, mortality and hospital admission in COPD. Thorax 2009;64:939-43. http://dx.doi.org/10.1136/thx.2009.113662

6. Simpson CR, Hippisley-Cox J, Sheikh A. Trends in the epidemiology of chronic obstructive pulmonary disease in England: a national study of 51,804 patients. $\mathrm{Br} J$ Gen Pract 2010;60:277-84. http://dx.doi.org/10.3399/bjgp10X514729

7. Department of Respiratory Disease, Pourvoo Hospital. Guidelines for COPD. 2012.

8. Department of Health. CHD National Service Framework. London: Department of Health, 1998.

9. Department of Health. Quality and Outcomes Framework Contract for Primary Care. London: Department of Health, 2011.

10. National Institute for Health and Clinical Excellence (NICE). Chronic Obstructive
Pulmonary Disease. NICE Clinical Guideline 101. 2010.

11. Department of Health. An Outcomes Strategy for Chronic Obstructive Pulmonary Disease and Asthma in England. London: Department of Health, 2011.

12. Haute Autorité de Santé. Guide du Parcours de Soins Broncopneumopathie Chronique Obstructive. 2012.

13. Agènce Regional de Santé. Programmes D'Actions/Maladies Chroniques: La Bronchopneumopathie Chronique Obstructive (BCPO) 2012-16. 2012.

14. Nolte E, Knai C, McKee M. Managing Chronic Conditions: Experience in Eight Countries. European Observatory Studies Series No 15. 2008

15. Hunger M, Thorand B, Schunk M, et al. Multimorbidity and health-related quality of life in the older population: results from the German KORA-Age study. Health Qual Life Outcomes 2011;9:53-63. http://dx.doi.org/10.1186/1477-7525-9-53

16. Bundesarztekammer. Program fur Nationale VersorgungsLeitlinien COPD. 2012.

17. Kinnula VL, Vasankari T, Kontula E, et al. The 10-year COPD programme in Finland: effects on quality of diagnosis, smoking, prevalence, hospital admissions and mortality. Prim Care Respir J 2011;20:178-83.

http://dx.doi.org/10.4104/pcri.2011.00024

18. Puska P. Successful prevention of non-communicable disease: 25 year experience with North Karelia Project in Finland. Public Health Med 2002;4(1):5-7.

19. Haahtela T, Tuomisto LE, Pietinalho A, et al. A 10-year asthma programme in Finland: major change for the better. Thorax 2006;61:663-7.

http://dx.doi.org/10.1136/thx.2005.055699

20. Eurostat. Brussels. 2012

\section{Available online at http://www.thepcrj.org}

